\title{
A política de inclusão escolar na perspectiva do professor da classe comum do município de Oeiras-Pl: desafios e dilemas
}

\author{
Jacyara Caroline da Costa Osório ${ }^{1}$ \\ https://orcid.org/0000-0002-6866-2858 \\ Ana Valeria Marques Fortes Lustosa ${ }^{2}$ \\ http://orcid.org/0000-0002-3540-9952
}

\section{Resumo}

Considerando as atuais políticas públicas destinadas à inclusão escolar de estudantes Público- alvo da Educação Especial (PAEE), esta pesquisa teve por objetivo investigar como se estrutura a política de inclusão escolar no município de Oeiras-PI, na perspectiva do professor da classe comum. Para tanto, adotou-se os parâmetros da abordagem qualitativa, do tipo descritiva. Participaram do estudo 10 professores que atuam na classe comum com estudantes PAEE em Oeiras-PI e que responderam ao questionário de avaliação da política de inclusão escolar na versão destinada aos professores da classe comum e a uma entrevista semiestruturada. Entre os resultados obtidos destacam-se o insuficiente conhecimento do professor da classe comum acerca das necessidades educativas dos estudantes PAEE, a ausência de apoio de outros profissionais e a infraestrutura pouco adaptada.

Palavras-chave: Políticas Públicas. Educação Especial. Inclusão Escolar. Oeiras-PI.

\begin{abstract}
Considering the current public policies aimed to school inclusion of Special Education Target Audience (PAEE), this research intended to investigate how the school inclusion policy is structured in the municipality of Oeiras-PI, in the perspective of the common class teacher. Therefore, it was chosen as parameters the qualitative approach, the descriptive type. The participants of this study were ten teachers who work in common class with PAEE students, in Oeiras - Pi. They answered the questionnaire, in order to

evaluate the school inclusion policy whose version was intended for common class teachers, and they attended to semi-structured interviews. As result, it is interesting to point out the insufficient knowledge of the common class teacher about the educational needs of PAEE students, lack of support from other professionals and the need for more adapted infrastructure.
\end{abstract}

Keywords: Public Policies. Special Education. School Inclusion. Oeiras-PI.

\footnotetext{
1 Mestre em Educação pela Universidade Federal do Piauí -UFPI; Técnica em Assuntos educacionais- IFPI. E-mail: jacyaraosorio@yahoo.com.br

2 Doutorado em Psicologia pela Universidade de Brasília. Professora da Universidade Federal do Piauí. E-mail: avfortes@gmail.com
} 
Introdução

O presente estudo integra um conjunto de pesquisas em rede com o propósito de avaliar a política de inclusão escolar implementada no Brasil e, com isso, visa colaborar para o processo de democratização de oportunidades de escolarização e melhorias no ensino de estudantes Público-alvo da Educação Especial (PAEE)³. Neste âmbito, desenvolve-se pesquisas no tocante à Avaliação da Política de Inclusão Escolar conforme a abordagem do Ciclo de Políticas, cuja intenção refere-se à produção de estudos em vários municípios do Brasil para entender como a inclusão se delineia no contexto da prática das escolas regulares, considerando a perspectiva do professor da classe comum.

Sob este enfoque, introduz-se que as Políticas Públicas de Inclusão do PAEE, que embora reafirmadas junto às bases legais atuais como a Constituição Federal (BRASIL, 1988), a Lei de Diretrizes e Bases da Educação (BRASIL, 1996), a Resolução CNE/CEB nº 02 (BRASIL, 2001) e o Documento norteador da Política Nacional de Educação Especial na Perspectiva da Educação Inclusiva (BRASIL, 2008), passaram por uma trajetória extensa de inoperância em função da omissão do Estado em detrimento do protagonismo de iniciativas particulares e de ações de instituições filantrópicas, tendo em vista que apenas a partir da década de 1970, o Estado implementa políticas que se comprometem diretamente com a educação do PAEE.

O contexto democrático, de luta pela garantia de direitos, impulsionou a adesão ao modelo social que começa a valorizar as pessoas como sujeitos de direitos e a entender que a deficiência está no ambiente social que não é adaptado para atender as necessidades de todos. Consequentemente, a sociedade necessita oferecer subsídios e suportes para que ocorra a inclusão escolar e social, inclusive dos segmentos que constituem a educação especial. Nessa perspectiva, as políticas educacionais pautadas na inclusão escolar têm início na década de 1990 e intensificam-se nos anos 2000.

Cabe salientar que a proposição da inclusão escolar no Brasil é importada de experiências vivenciadas em países desenvolvidos relacionadas à matrícula de pessoas com deficiência em salas de ensino comum, ou seja, em realidades diferentes das de desigualdade e segregação existentes no contexto brasileiro. Além disso, refere-se à influência de agências multilaterais, ao conduzir acordos internacionais dos quais o Brasil é signatário, atrelandoos à atual legislação nacional (MENDES, 2006; KASSAR, 2014).

Com a política de inclusão escolar, os organismos multilaterais determinam e patrocinam as diretrizes que devem ser utilizadas no sistema educacional brasileiro, promovendo uma alternativa barata e que envolve pouco trabalho para promover a pseudoparticipação dos indivíduos PAEE. Em se tratando desta política de inclusão escolar na realidade brasileira faz-se necessário destacar que foi no Governo Luís Inácio Lula da Silva (2003-2006/ 2007-2010) que uma série de documentos foi sancionada com o fim de proporcionar a matrícula do aluno PAEE na classe comum em caráter complementar e suplementar através do Atendimento Educacional Especializado (AEE), realizado, preferencialmente, nas salas de recursos multifuncionais (SRMs).

Neste contexto, cabe destacar as seguintes bases legais: a Resolução CNE/CEB nº 02/2001 (BRASIL, 2001) que institui as Diretrizes Nacionais para a Educação Especial na Educação Básica e a Portaria Normativa ${ }^{\circ} 13$ (BRASIL, 2007), que cria o Programa de Implantação de Sala de Recursos Multifuncionais (SRMs). No ano seguinte, em 2008, institui através do Decreto $n^{\circ}$ 6.571/2008 (BRASIL, 2008) revogado posteriormente pelo

Considera-se que o PAEE é composto por pessoas com deficiência, transtornos globais do desenvolvimento e altas habilidades/superdotação 
Decreto $n^{\circ}$ 7611/2011 (BRASIL, 2011), a política pública de financiamento no âmbito do Fundo de Manutenção e Desenvolvimento da Educação Básica e de Valorização dos Profissionais da Educação - FUNDEB, estabelecendo o duplo cômputo das matrículas do PAEE. Nesta linha, grifa-se o Atendimento Educacional Especializado (AEE) como serviço mais representativo, uma vez que é assegurado no contraturno das atividades comuns para complementar ou suplementar as ações pedagógicas voltadas para desenvolver a aprendizagem e a participação desta parcela da população.

As políticas públicas que orientam a inclusão escolar do PAEE na escola regular supõem o aprimoramento dos sistemas de ensino, o que implica a revisão de concepções e paradigmas educacionais ultrapassados, mas ainda em voga, de forma a possibilitar o desenvolvimento adequado da aprendizagem de cada educando. Sendo assim, torna-se imperativo o desenvolvimento de um trabalho escolar de qualidade que ceda lugar ao desenvolvimento de novas atitudes, de novas formas de atuação e interação na escola. Almeja-se com isso uma pedagogia que, por sua vez, suscite a construção de uma sociedade que respeite a dignidade e as diferenças humanas. Caso contrário, corre-se o risco de perpetuar a condição de exclusão, provocada pelo fracasso escolar, pelos altos índices de reprovação e baixos níveis de aprendizagem desses alunos (MARTINS, 2006).

Segundo este enfoque, argumenta-se que o número expressivo de matrículas dos estudantes PAEE nas escolas comuns não é determinante para a sua efetiva inclusão. Isto porque, para que realmente ocorra a inclusão, é necessário o investimento em políticas de apoio e em serviços especializados, o envolvimento de toda a comunidade educacional, a participação da família no âmbito escolar, a formação constante do professor da classe comum e também do professor especializado que atua na SRM, o planejamento de um trabalho colaborativo entre estes profissionais, além de incentivo e consolidação da crença na educação de todos (MENDES, 2010).

Em vista desse quadro, o despertar para o estudo aprofundado sobre esse tema teve início durante o contato da pesquisadora com a realidade de uma escola municipal de Teresina, durante estágio de docência da pesquisadora, no qual atuou como auxiliar de uma turma para ministrar aulas sozinha, sem o preparo teórico-prático que deve ter o profissional da classe comum. A pesquisa relatada neste artigo foi desenvolvida com o propósito de buscar respostas para o seguinte problema: Como os professores da classe comum percebem a inclusão escolar no município de Oeiras-PI? Que dificuldades os professores da classe comum observam na implementação da política de inclusão escolar no município de Oeiras- PI?

Sabe-se que as políticas estão sujeitas a reinterpretações que podem representar transformações significativas na proposta da política original, isto porque as políticas não são meramente implementadas, mas são lidas e aplicadas por atores sociais levando em conta a realidade de atuação profissional a que estão submetidos (BALL, MAGUIRE, BRAUN, 2016; MAINARDES, 2011). Desta maneira, o professor adquire importante papel na ressignificação das políticas, uma vez que para pô-las em prática é necessário um exercício de criatividade e adaptação às situações adversas.

As políticas raramente dizem-lhe exatamente o que fazer, elas raramente ditam ou determinam a prática, mas algumas mais do que outras estreitam a gama de respostas criativas. Isso é em parte porque os textos de políticas são tipicamente escritos em relação à melhor de todas as escolas possíveis, escolas que só existem no imaginário febril de políticos, funcionários públicos e conselheiros e em relação a contextos fantásticos. Estes textos não podem simplesmente serem implementados! Eles têm de ser traduzidos a partir do texto para a ação - colocados "em" prática- em relação à história e ao contexto, com os recursos disponíveis (BALL et al., 2016, p.14). 
É recorrente encontrar depoimentos de docentes insatisfeitos com as condições precárias em termos de estrutura, formação e valorização profissional para viabilização da política no contexto escolar. Sendo assim, entende-se que no ato da escrita das políticas educacionais não são consideradas as fragilidades da escola brasileira, pois estas são baseadas em modelos românticos, pouco realistas, muitas vezes importados de outras realidades com inexpressiva viabilidade de aplicação nas instituições educacionais do Brasil.

Nos últimos anos, os educadores de escolas públicas brasileiras têm se surpreendido com a presença de alunos PAEE matriculados em suas turmas, em diversos níveis de escolarização. Essa situação é resultante da política de inclusão escolar, que tem sido implantada expressivamente desde 2003. Essa política representa uma quebra de paradigmas pautados no modelo médico de entender a deficiência; e garante o direito das pessoas PAEE às oportunidades de educação na escola comum, matriculadas na sala comum e, em caráter complementar e/ou suplementar, recebendo AEE na sala de recursos multifuncionais.

Apesar do progresso que a inclusão escolar propicia para a sociedade, a partir de relatos de professores em pesquisas realizadas em várias regiões do Brasil (TANNÚS-VALADÃO; MENDES, 2015), pode-se afirmar que esta é uma política constantemente recriada na prática pedagógica, uma vez que os professores que recebem alunos PAEE, em geral, não têm acesso a formações que os qualifiquem para atender as especificidades deste segmento. Ademais, as ações governamentais não viabilizam uma dinâmica escolar que possibilite um diálogo mais próximo entre o professor da SRM e o professor da classe comum, descumprindo a previsão de ensino colaborativo estabelecida na Resolução CNE/CEB no 02 (BRASIL, 2001). A falta de tempo e valorização profisssional para realização de um planejamento diferenciado, dentre outros entraves que dificultam a aplicação da Política como se apresenta nos documentos.

Logo, postula-se que a inclusão do aluno PAEE na escola regular configura-se como um processo desafiador a ser construído a várias mãos. Depende, pois, de um esforço coletivo que obriga a uma avaliação das políticas públicas disseminadas ao longo do tempo e da postura de pesquisadores, políticos, profissionais, familiares e pessoas com deficiência, a fim de trabalhar em prol do êxito educacional de todos.

\section{Procedimentos metodológicos}

A pesquisa pautou-se segundo preceitos qualitativos de investigação, uma vez que, em educação, assume um caráter flexível a depender do contexto em que é realizada. Esse tipo de estudo busca essencialmente a compreensão dos fenômenos segundo a óptica dos participantes da investigação (BOGDAN; BIKLEN, 1994).

Os participantes desta pesquisa foram 10 professores regentes de classes comuns do ensino fundamental da rede municipal de educação que possuíam alunos PAEE, a partir dos seguintes critérios de escolha: ser professor da classe comum do ensino fundamental da rede municipal de Oeiras e ter alunos público-alvo da educação especial na sala de aula no momento da realização da pesquisa.

Como instrumentos de coleta de informações foram utilizados: o questionário de Avaliação da Política de Inclusão Escolar: professor de classe comum (TANNÚS-VALADÃO; VILLARONGA; LACERDA; MENDES, 2016), elaborado para o Instituto Nacional de Estudos e Pesquisa Educacionais Anísio Teixeira (INEP) com o 
intuito de avaliar a Política de Educação Especial, no âmbito do grupo de estudo do GPFOREESP da Universidade Federal de São Carlos - UFSCar.

Complementarmente, utilizou-se um roteiro de entrevista semiestruturada com os professores da classe comum, a fim de aprofundar questões relacionadas à implementação da política de inclusão escolar no município e à formação docente disponibilizada para atender esta demanda, uma vez que a entrevista na pesquisa qualitativa, a partir da interação entre os envolvidos, permite uma melhor compreensão dos significados e valores sociais emergidos das vivências (FRASER; GONDIM, 2004).

Para fins éticos do estudo, os participantes da pesquisa assinaram Termos de Consentimento Livre e Esclarecido (TCLE) e foram identificados com nomes fictícios ${ }^{4}$ para resguardar os critérios éticos da pesquisa e preservar o anonimato das fontes. O Quadro 1 descreve o perfil dos entrevistados.

Quadro 1 - Perfil dos participantes da pesquisa

\begin{tabular}{|c|c|c|c|c|c|}
\hline Professor(a) & Idade & Sexo & Formação Inicial & Pós-Graduação & $\begin{array}{l}\text { Tempo de } \\
\text { experiência }\end{array}$ \\
\hline PAZ & 44 anos & $\mathrm{F}$ & $\begin{array}{l}\text { Lic. Plena em Letras- } \\
\text { Português }\end{array}$ & $\begin{array}{c}\text { Esp. em Língua } \\
\text { Portuguesa e literatura }\end{array}$ & De 21 a 30 anos \\
\hline COOPERAÇÃO & 42 anos & $\mathrm{F}$ & $\begin{array}{l}\text { Lic. em Letras- } \\
\text { Português }\end{array}$ & $\begin{array}{l}\text { Esp. em educação } \\
\text { especial e inclusiva }\end{array}$ & De 11 a 20 anos \\
\hline EMPATIA & 39 anos & $\mathrm{F}$ & $\begin{array}{l}\text { Lic. Plena em } \\
\text { Pedagogia }\end{array}$ & Esp. em Psicopedagogia & De 11 a 20 anos \\
\hline ESTIMA & 49 anos & $\mathrm{F}$ & $\begin{array}{l}\text { Lic. Plena em } \\
\text { História }\end{array}$ & $\begin{array}{l}\text { Esp. em Gestão pública } \\
\text { e História do Brasil }\end{array}$ & De 21 a 30 anos \\
\hline RESPEITO & 55 anos & M & $\begin{array}{c}\text { Lic. Plena em } \\
\text { Ciências da natureza } \\
\text { e matemática }\end{array}$ & $\begin{array}{l}\text { Esp. em Saúde do } \\
\text { Escolar }\end{array}$ & De 21 a 30 anos \\
\hline UNIÃO & 46 anos & $\mathrm{F}$ & $\begin{array}{l}\text { Lic. Plena em } \\
\text { Pedagogia }\end{array}$ & Esp. em Psicopedagogia & De 11 a 20 anos \\
\hline AFEIÇÃO & 41 anos & $\mathrm{F}$ & $\begin{array}{l}\text { Lic. Plena em Letras- } \\
\text { Português }\end{array}$ & $\begin{array}{l}\text { Esp. em Gramática e } \\
\text { Literatura }\end{array}$ & De 11 a 20 anos \\
\hline ALEGRIA & 39 anos & $\mathrm{F}$ & $\begin{array}{l}\text { Lic. Plena em Letras- } \\
\text { Português }\end{array}$ & Esp. em Gramática & De 11 a 20 anos \\
\hline CONFIANÇA & 40 anos & $\mathrm{F}$ & $\begin{array}{l}\text { Lic. Plena em Letras- } \\
\text { Português }\end{array}$ & Esp. em Gramática & De 11 a 20 anos \\
\hline TOLERÂNCIA & 50 anos & $\mathrm{F}$ & $\begin{array}{l}\text { Lic. Plena em } \\
\text { Pedagogia }\end{array}$ & $\begin{array}{l}\text { Esp. em Gestão e } \\
\text { docência }\end{array}$ & De 11 a 20 anos \\
\hline
\end{tabular}

Fonte: Elaborado pela autora

Conforme descrição presente no Quadro 1, analisa-se que todos os professores pesquisados trabalham com alunos PAEE em classes comuns de escolas regulares e têm idade entre 39 e 55 anos, sendo $90 \%$ do sexo feminino. Diante do perfil apresentado é possível observar que apesar de os sujeitos da pesquisa terem situação funcional estável, sendo todos concursados no trabalho atual, apenas as professoras Empatia, União e Tolerância têm

\footnotetext{
4 Para tanto, foram denominados com nomes de sentimentos relacionados à inclusão, são eles: Paz, Cooperação, Empatia, Estima, União, Afeição, Alegria, Confiança, Tolerância - para designar as participantes do sexo feminino; e Respeito - para o professor do sexo masculino.
} 
formação em Licenciatura Plena em Pedagogia e, portanto, têm habilitação mínima para atuar nas séries iniciais do ensino fundamental, inclusive com alunos PAEE, já que por terem feito este curso, pressupõe-se que possuem conhecimentos básicos sobre educação especial.

Os participantes, de modo geral, apresentam um tempo significativo de formação em serviço, podendo-se traçar um período de 11 a 30 anos, entre aqueles com menor tempo e aqueles que possuem mais anos no desempenho da função docente. No tocante à experiência no magistério, destaca-se que os participantes da pesquisa possuem uma licenciatura. Consoante a isso, acrescenta-se o agravante de que a formação inicial já foi concluída há bastante tempo, pois podem estar desatualizadas no tocante à demanda das políticas de inclusão escolar.

Em estudo detalhado, observou-se que as professoras Paz, Estima, Tolerância, Alegria e Cooperação concluíram os estudos de formação inicial em diversas licenciaturas há mais de 15 anos. No que diz respeito às professoras União, Confiança e Afeição, estas relatam que o tempo de conclusão da graduação está entre 10 a 15 anos. Já os professores Respeito e Empatia destacam que se formaram há mais de seis e menos de 10 anos. Destes, apenas as professoras Cooperação, Tolerância e Empatia relataram terem tido conteúdos relacionados à educação especial contemplados no curso. Destaca-se com isso, que estas são exatamente as professoras que têm formação inicial em Pedagogia. Os demais professores não tiveram noções introdutórias acerca do trabalho pedagógico com estudantes PAEE por não possuírem formação inicial adequada para subsidiar o trabalho docente com essas crianças que estudam na educação infantil e no ensino fundamental menor $\left(1^{\circ}\right.$ a $5^{\circ}$ ano).

Observa-se ainda, que todos os professores participantes têm pós-graduação latu senso, mas apenas a professora Cooperação atualizou seus conhecimentos na área da Educação Especial e Inclusiva. Neste sentido, convém salientar o nítido entrave relacionado à formação inicial dos professores das escolas municipais para atuarem no atendimento educacional de alunos da educação infantil e das séries iniciais do ensino fundamental em uma perspectiva inclusiva, uma vez que sete, dentre os 10 participantes não adquiriram, a nível de graduação, conhecimentos relacionados à Educação Especial, já que são formados em Licenciaturas diversas.

O Quadro 2, apresenta a situação de trabalho a que estão submetidos os professores da classe comum, levando em conta a quantidade de turmas e o número de alunos atendidos, incluindo o público alvo da educação especial nas salas em que lecionam.

Quadro 2 - Caracterização do trabalho atual

\begin{tabular}{|c|c|c|c|c|}
\hline Professor(a) & $\begin{array}{l}\text { Etapa em que } \\
\text { leciona }\end{array}$ & $\begin{array}{l}\mathrm{N}^{0} \text { de } \\
\text { turmas }\end{array}$ & $\mathrm{N}^{0}$ de alunos em sua sala & $\begin{array}{l}\mathrm{N}^{0} \text { de alunos PAEE em sua } \\
\text { sala }\end{array}$ \\
\hline PAZ & $4^{\circ}$ e $5^{\circ}$ ano & 2 & $\begin{array}{c}\text { De } 21 \text { a } 30 \text { alunos em cada } \\
\text { turma }\end{array}$ & $\begin{array}{l}5 \text { alunos em apenas } 1 \text { das } \\
\text { turmas }\end{array}$ \\
\hline COOPERAÇÃO & $4^{\circ}$ e $5^{\circ}$ ano & 2 & $\begin{array}{c}\text { De } 21 \text { a } 30 \text { alunos em cada } \\
\text { turma }\end{array}$ & $\begin{array}{l}5 \text { alunos (sendo } 4 \text { em uma } \\
\text { turma e } 1 \text { em outra) }\end{array}$ \\
\hline Professor(a) & $\begin{array}{l}\text { Etapa em que } \\
\text { leciona }\end{array}$ & $\begin{array}{c}\mathrm{N}^{0} \text { de } \\
\text { turmas }\end{array}$ & $\mathbf{N}^{0}$ de alunos em sua sala & $\begin{array}{c}\mathrm{N}^{0} \text { de alunos PAEE em sua } \\
\text { sala }\end{array}$ \\
\hline EMPATIA & $3^{\circ}$ ano & 1 & De 21 a 30 alunos & 2 alunos \\
\hline ESTIMA & $1^{\circ}$ ano & 1 & De 21 a 30 alunos & 1 aluno \\
\hline
\end{tabular}




\begin{tabular}{|c|c|c|c|c|}
\hline RESPEITO & $5^{\circ}$ ano & 1 & De 31 a 40 alunos & 3 alunos \\
\hline UNIÃO & $5^{\circ}$ ano & 1 & De 0 a 20 alunos & 1 aluno \\
\hline AFEIÇÃO & $5^{\circ}$ ano & 1 & De 0 a 20 alunos & 1 aluno \\
\hline ALEGRIA & $2^{\circ}$ ano & 2 & De 0 a 20 alunos & $\begin{array}{c}2 \text { alunos em apenas uma } \\
\text { turma }\end{array}$ \\
\hline CONFIANÇA & $1^{\mathrm{o}}$ ano & 2 & $\begin{array}{c}\text { De } 21 \text { a } 30 \text { alunos em cada } \\
\text { turma }\end{array}$ & $\begin{array}{l}5 \text { alunos (sendo } 2 \text { em uma } \\
\text { turma e } 3 \text { na outra) }\end{array}$ \\
\hline TOLERÂNCIA & $3^{\circ}$ ano & 2 & $\begin{array}{c}\text { De } 21 \text { a } 30 \text { alunos em cada } \\
\text { turma }\end{array}$ & $\begin{array}{l}1 \text { aluno, em apenas uma das } \\
\text { turmas. }\end{array}$ \\
\hline
\end{tabular}

Fonte: Elaborado pela autora

O Quadro 2 evidencia que todos são professores das séries iniciais do ensino fundamental, atuam em salas comuns com 20 a 40 alunos, dentre os quais até quatro são do público-alvo da educação especial; possuem situação funcional estável e recebem de um a quatro salários mínimos. Destes, 70\% cumprem uma carga horária semanal de 40 horas. Esses dados indicam também que os professores da educação básica estão submetidos à elevada cargahorária de trabalho, resultante de um plano de carreira pouco promissor.

Observa-se, ainda, que a maioria precisa se deslocar de uma escola para outra e trabalhar por dois ou até três turnos para conseguirem remuneração necessária para viver dignamente, situação que dificulta a organização de tempo para planejar atividades diferenciadas ou personalizadas às demandas do público-alvo da educação especial, o investimento em formação específica, bem como inviabiliza a articulação com o professor da Sala de Recursos Multifuncional.

Outra questão a ser explorada refere-se à formação continuada dos participantes. Embora seja notória a busca por qualificação profissional, visualizada na informação de que todos os professores têm alguma pós-graduação realizada nos últimos 5 anos, a maioria dos docentes pesquisados não possui pós-graduação aplicável à área em que atuam, tampouco a conhecimentos referentes à Educação Especial e/ou inclusiva. Neste sentido, apenas a professora Cooperação tem pós-graduação com direcionamento para a inclusão escolar. Esta realidade formativa justifica o despreparo epistemológico, teórico e prático dos professores da classe comum na Educação desse segmento.

\section{Resultados e discussão}

Em tempos atuais, a tendência nacional de inclusão escolar representada pela matrícula de alunos PAEE em escolas e classes comuns e, em caso complementar ou suplementar, nas salas de recursos multifuncionais é verificada também na realidade educacional de Oeiras- PI. Sendo assim, observa-se que esta política educacional, ao tempo em que desconstrói as discriminações, possibilita o desenvolvimento de ações no âmbito escolar que garantem o acesso de todos. No entanto, sua implantação apresenta falhas que muitas vezes podem comprometer o desenvolvimento do processo ensino-aprendizagem do público atendido. 


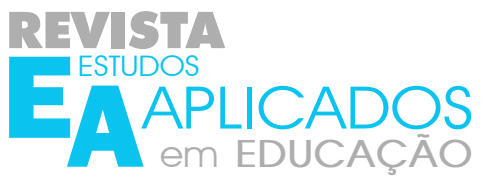

Sendo assim, corroborando estudos realizados por Mendes et al. (2014) e Oliveira (2016), argumenta-se que as dificuldades encontradas em outros contextos e em outros tempos escolares, também estão presentes na realidade escolar oeirense. Destacam-se aqueles referentes a problemas de espaço físico e material, elevado número de alunos, visitas esporádicas do professor especialista à sala comum, falta de tempo para formação e planejamento, ausência de formações relacionadas à área da educação especial e pouco envolvimento de outros profissionais, dentre outros. Baseado nas entrevistas dos participantes, elucida-se as seguintes subcategorias:

Quadro 3 - Dificuldades na implementação da Inclusão dos estudantes PAEE

\begin{tabular}{|l|c|c|}
\hline \multicolumn{1}{|c|}{ SUBCATEGORIAS } & PROFESSORES & FREQUÊNCIA \\
\hline $\begin{array}{l}\text { Quantidade elevada de alunos por } \\
\text { sala }\end{array}$ & Respeito & 1 \\
\hline $\begin{array}{l}\text { Falta de tempo para planejar } \\
\text { atividades }\end{array}$ & Empatia & 1 \\
\hline $\begin{array}{l}\text { Pouco conhecimento na área da } \\
\text { Educação especial }\end{array}$ & Estima, Paz e Tolerância & 3 \\
\hline $\begin{array}{l}\text { Ausência de apoio de outros } \\
\text { profissionais }\end{array}$ & Cooperação e Alegria & 2 \\
\hline Escassez de recurso didático & Confiança e União & 2 \\
\hline Preconceito & Afeição & 1 \\
\hline
\end{tabular}

Fonte: Informações da pesquisa

\section{Quantidade elevada de alunos por sala}

No contexto da prática das escolas comuns brasileiras, e em especial as do lócus investigado, é possível vislumbrar constantes reclamações advindas dos docentes no que tange ao excesso de alunos em sala de aula, à diversidade de ritmos de aprendizagem que ali se encontram e, portanto à dificuldade que estes profissionais têm de desenvolver um planejamento que promova a aprendizagem de todos. É sobre este aspecto que a fala do professor Respeito faz referência.

\footnotetext{
Uma das dificuldades tremendas é a quantidade de alunos e a falta de monitores também. É uma realidade desumana, eu na sala com 34 alunos, dentre eles, 03 com laudos, você fica sem saber o que fazer porque não tem como dar assistência a uma criança daquela. Os nossos alunos hoje, os normais, são agressivos, a gente tem que está no pé então não dá para dar atenção apenas a uma criança e deixar as outras de lado (RESPEITO).
}

Diante deste desafio, o professor menciona, ainda, a necessidade de monitores para auxiliarem nas atividades desenvolvidas no contexto escolar, tendo em vista a inclusão do estudante da educação especial. Segundo suas palavras, não há tempo suficiente para dar atenção a este aluno, tendo em vista que as atividades propostas não são similares às realizadas por outros alunos. 
Destaca-se que o professor precisa estar muito mais preparado para atender a diversidade de situações presentes na sala de aula no contexto de inclusão escolar, bem como transformá-las em instrumentos de promoção da aprendizagem de todos (GLAT; NOGUEIRA, 2003). Neste caso, seria conveniente a existência de dois profissionais, o professor da classe comum e o professor da educação especial, com atuação na sala de aula em regime de colaboração, como vem ocorrendo em outros países.

\section{Falta de tempo para planejar atividades}

No que se refere à quantidade excessiva de alunos por sala, a professora Empatia destaca a falta de tempo para planejar as atividades escolares como uma grande vilã do processo de escolarização deste alunado.

[citação] O problema da turma que são 29 alunos, a própria falta de tempo para se voltar mais para aquele ali naquela sala de aula [...] estas são as maiores dificuldades[...]. Eu não tenho com quem dividir conflitos. Eu mesma também sou a professora de AEE e me sento para ver o que foi que aquele aluno avançou, vejo o que precisa estimular mais, o que é preciso trabalhar mais com ele para tentar desenvolver atividades dele (EMPATIA).

Além disso, a professora que recebe dentre seus alunos, 01 com deficiência intelectual e 01 aluno com autismo, argumenta que não consegue atender as necessidades educacionais deles, uma vez que desenvolve o trabalho na classe comum pela manhã e, durante a tarde, atua no Atendimento Educacional Especializado com eles e com outros alunos. Pondera também que não tem o apoio de outros profissionais da escola para desenvolver atividades conjuntas. Nessa direção, Mendes et al. (2014) apontam a necessidade de formação de equipes colaborativas de profissionais da Educação Especial para oferecer suporte ao professor da classe comum, com a utilização de materiais de apoio e outros subsídios que favoreçam a qualidade do ensino.

Diante do contexto laboral do professor da classe comum de Oeiras que, em geral, trabalha 40 horas semanais, a inclusão de estudantes PAEE torna-se um desafio, uma vez que este profissional não dispõe de tempo para ajustar as atividades às reais demandas de aprendizagem que este público exige. As precárias condições de trabalho devem-se ao insuficiente investimento governamental no que se refere a suportes, apoios e serviços às escolas comuns, bem como a uma política que não valoriza os profissionais do magistério. Compreende-se, assim, que os professores executores da política de inclusão escolar interpretam, traduzem e fazem outras leituras desta conforme as condições e os contextos a que estão submetidos (BALL; MAGUIRE; BRAUN, 2016).

Nesta ótica, para que os professores efetivem a inclusão escolar conforme a legislação, fazem-se necessárias políticas e programas que garantam uma reestruturação física e curricular; profissionais capacitados e especialistas para atender ao estudante público-alvo da educação especial, a partir de uma proposta colaborativa, com serviços de apoio e outros dispositivos que favoreçam a aprendizagem desses alunos. Para tanto, é necessário investimento na valorização do plano de carreira do profissional da educação, formação de professores e trabalho colaborativo entre a comunidade escolar, como preconizam Mendes (2006) e Dutra (2018). 


\section{Pouco conhecimento na área da Educação Especial}

Enfatiza-se que o compromisso da escola enquanto espaço inclusivo é com o êxito dos alunos, pois não se trata apenas de inseri-los fisicamente nas dependências de uma escola comum, mas fazê-los aproveitar a experiência, se necessário com suportes, de modo que lhes renda aprendizagens satisfatórias. Ocorre que, na prática escolar muitas condições ainda são desfavoráveis à efetiva inclusão escolar, sobretudo, no que tange à formação do professor regente da classe comum.

A formação de professores do ensino comum é um dos requisitos básicos para a culminância da escola enquanto espaço inclusivo, principalmente porque propicia a exclusão de práticas tradicionais de preconceito ou intolerância a esse público, além de conferir a compreensão das necessidades educativas e, assim, possibilitar o desenvolvimento de planos de ação diferenciados, bem como afirmar o potencial de aprendizagem de todos os alunos (FERREIRA et al., 2015).

Consoante a isso, os professores Estima, Paz e Tolerância, nenhum com formação inicial em Pedagogia ou áreas afins à Educação Especial, demonstram que o sucesso da política de inclusão escolar, de acordo com suas perspectivas, está relacionado à formação do professor. Essas professoras consideram que precisam de um estudo voltado para atender as dificuldades desses alunos, bem como para realizar um planejamento individualizado para este contingente do alunado. Nesta argumentação, observa-se que estes profissionais avaliam a formação que receberam como insuficiente para possibilitar a efetiva inclusão dos alunos público-alvo da educação especial, uma vez que não entendem todas as potencialidades que eles podem desenvolver.

Precisaria de um estudo voltado para atender as dificuldades daqueles alunos como planejamento voltado só para eles, para atender as necessidades deles (PAZ).

Nós professores estamos sozinhos neste processo, o menino é colocado lá na sala e pronto, não temos formação nesta área e muitas vezes não sabemos o que fazer, nos sentimos impotentes (TOLERÂNCIA).

Corroborando as falas das professoras citadas, Estima complementa que embora já tenha participado de algumas formações, em muitas situações, não sabe como proceder. Além disso, o estudante da educação especial sente-se como se não estivesse participando do processo, o que muitas vezes, resulta em indisciplina. Destacam ainda que o fato de não possuírem uma formação inicial e continuada, que propicie a prática inclusiva, compromete o trabalho pedagógico no que diz respeito ao atendimento das especificidades desses educandos na classe comum.

Estudos desenvolvidos por Silva e Abreu (2016) apontam a ausência de formação do professor da classe comum, o que acarreta certo distanciamento em relação ao professor especialista, e que eles não o procuram para dirimir possíveis dúvidas ou para auxiliar na adaptação de atividades. No tocante à formação continuada, alguns professores relatam a dificuldade que encontram em fazê-la quando esta não é ofertada pela própria Secretaria de Educação, pois, em geral, não são liberados do trabalho se precisarem se ausentar para esse fim. Outro problema, segundo eles, é a dificuldade de aplicar o que aprendem nessas formações, já que o planejamento e as ações curriculares são uniformizados em todas as escolas do município. Outros professores, como Afeição e União, relatam que a rede municipal até oferece cursos de formação, mas nenhum diretamente relacionado ao aluno público-alvo da educação especial. 
Com base em suas considerações, verifica-se que os professores esperam que a escola disponibilize a formação continuada para subsidiar suas práticas. Essa observação vai de encontro ao que é proposto pelas tendências atuais para a formação de professores, como é o caso do trabalho de Garcia (2013), que supõe que os professores sejam responsáveis pelo seu constante processo de atualização para atender e conviver com a complexidade de temas que adentram os muros das escolas a cada dia. Neste cenário, pode-se inferir que a formação para a inclusão supõe uma atitude crítico-reflexiva que garanta ao professor os constructos para adquirirem um pensamento autônomo e que facilite as dinâmicas de autoformação.

Sendo assim, torna-se imperativo que os professores adquiram conhecimentos que os façam abandonar antigas e inadequadas formas de ensinar, pautadas em padrões escolares homogêneos, que os façam refletir na e sobre sua prática e, assim, construam situações de aprendizagem com foco nas potencialidades do aluno e que favoreçam a participação e autonomia de todos os envolvidos no processo. Esta linha de pensamento é compatível com o que postulam Glat e Nogueira (2003); Oliveira (2010) e Garcia (2013).

Além disso, é importante destacar que as formações devem culminar na superação de formas fragmentadas, descontextualizadas e insuficientes de habilitação docente, uma vez que tais formulações podem comprometer o trabalho educativo e desconsiderar a realidade de cada sala de aula (DENARI, 2006).

\section{Ausência de apoio de outros profissionais}

É salutar a consideração de que a possibilidade de acesso à escola comum pelo PAEE representa uma conquista nunca vista no histórico de políticas educacionais deste país. No entanto, a escola precisa se organizar para favorecer o envolvimento de toda a comunidade educacional no processo inclusivo dos estudantes público alvo da educação especial para que se sintam pertencentes ao ambiente escolar, acolhidos, aceitos e apoiados por seus pares. Para tanto, é imprescindível o trabalho colaborativo de todos os profissionais da escola. (MARTINS, 2006; MENDES, 2010).

Não obstante essa consideração, nas escolas de Oeiras, em alguns casos, não é possível visualizar a colaboração dos profissionais no tocante à inclusão efetiva destes estudantes. Em alguns depoimentos é bem presente o sentimento que os professores têm de solidão, em função da falta de apoio dos profissionais da escola e da ausência de profissionais especializados na área. Essa problemática é verificada na fala das seguintes professoras:

\footnotetext{
A minha maior dificuldade é em relação a essas alunas que tenho esse ano, não sei direito se estão aprendendo ou não, queria contar com o apoio de um profissional que saiba lidar com essas deficiências para orientar a gente, propor atividades, tarefas pra gente fazer com elas, para eles participarem das aulas (ALEGRIA). A gente precisa de muitos profissionais para que realmente essa criança seja inclusa porque só o professor sozinho junto com a coordenação de multimídia ainda está muito difícil porque têm crianças que tem necessidade maior e a gente sente a necessidade de outros profissionais para que essa criança tenha realmente um atendimento adequado (COOPERAÇÃO).
}

$\mathrm{Na}$ fala da professora Cooperação fica evidente que não há a prática do ensino colaborativo em sala de aula, como proposta pela Resolução $n^{\circ}$ 02/2001, uma vez que considera estar sozinha no processo, mesmo que sua escola disponibilize o serviço de AEE. Além das queixas feitas pelas professoras Alegria e Cooperação com relação à ausência de profissional especializado em Educação Especial para auxiliar nas atividades, na proposição 
e diferenciação de atividades escolares destinadas aos alunos público-alvo da educação especial, outros professores pesquisados, como Respeito, Paz e Confiança, mencionaram a necessidade de contratação de monitores e a pouca participação dos profissionais da escola no processo inclusivo.

\section{Escassez de recursos didáticos}

Ainda no rol dos empecilhos para a inclusão escolar por parte do professor da sala comum, destaca-se, entre outros já mencionados, a carência de materiais didático-pedagógicos (SILVA; ABREU, 2016). A carência de materiais de suporte à prática didático- pedagógica do professor da classe comum, especialmente, na confecção de materiais adaptados para favorecer a aprendizagem dos estudantes, também é uma realidade nas escolas de Oeiras, conforme evidencia o depoimento da professora Confiança.

A principal dificuldade exatamente é a de preparar a atividade para aquele aluno quando a gente não tem subsídio nenhum que ajude, não tem recurso, não tem nada na escola. Como é que você vai adaptar alguma coisa se não tem como adaptar? Não tem esse apoio e pouco tempo (CONFIANÇA).

A professora em questão atribui essa escassez de materiais à falta de apoio financeiro da escola. Observa-se na sua fala o desejo de realizar um trabalho inclusivo, mesmo diante da falta de tempo e das condições escolares inadequadas. Ressalte-se, ainda, que esta também é uma queixa de outros professores que, inclusive, alegaram a necessidade de fazer as próprias adaptações no material, muitas vezes, utilizando recursos próprios para garantir a participação desse alunado nas atividades escolares. Professores como, por exemplo, União, também reclamam sobre as condições de adaptação dos espaços físicos, tendo em vista que não há espaços amplos e adaptados para atender as necessidades dos alunos.

\section{Preconceito}

Além dos entraves já apresentados para a consolidação da inclusão escolar, a professora Afeição acrescenta o preconceito existente em relação aos alunos público-alvo da educação especial como uma barreira atitudinal que dificulta o desenvolvimento das atividades escolares, a interação entre seus pares e a confiança nas suas potencialidades. Diante dessa análise, infere-se que as marcas históricas de segregação escolar daqueles que apresentam características incompatíveis com as expectativas do sistema educacional das escolas comuns ainda estão presentes no contexto da prática das escolas de Oeiras. A fala da professora ilustra essa dificuldade: "As principais dificuldades que eu vejo são a estrutura das salas, a falta de formação dos professores, o preconceito" (AFEIÇÃO).

O professor da classe comum emerge como figura central no que se refere à provocação de toda a comunidade escolar para flexibilizar as estruturas rígidas em que se assentam as práticas pedagógicas da escola tradicional, que dificultam a reformulação nas formas de ensinar, de se comunicar e de se relacionar com o conteúdo e com o outro para garantir a inclusão e a aprendizagem de todos. Cabe, inicialmente, a este profissional, a condução do processo 
de transformação da prática pedagógica e o abandono das antigas e preconceituosas ainda existentes no ambiente escolar, como apontado por autores como Oliveira (2010) e Bueno (2016).

Uma observação a ser feita, com relação a este aspecto, é que alguns professores ainda não se apropriaram das expressões e/ou terminologias que asseguram um tratamento de respeito ao público-alvo da educação especial e ajudam a prevenir certos tipos de discriminação ou preconceito. Alguns utilizam termos como "deficientes"; "retardados" ou "deficientes mentais" quando querem se referir à deficiência intelectual. Expressões como essas carregam a marca histórica de descrença na educação especial, baseada no modelo clínico, de que estas pessoas não podem aprender ou que a deficiência está na pessoa e não no meio social, conforme denunciam Glat e Nogueira (2003), Lepri (2012) e Mendes (2006; 2010).

Nessa linha de pensamento, é imprescindível que o professor abandone as posturas que instiguem a intolerância, a discriminação e/ou a exclusão de alunos que não se enquadram nos padrões homogêneos escolares. Em outras palavras, é preciso que use seu poder educativo para favorecer a aprendizagem e disseminar a valorização das diferenças individuais, valendo-se de variadas estratégias de ensino, com foco nas potencialidades do educando e não na deficiência.

\section{Considerações finais}

Os resultados obtidos na pesquisa evidenciam a maneira precária como está sendo implementada a política de inclusão escolar no contexto da prática do professor da classe comum da rede municipal de Oeiras-PI. Contudo, o mero fato de se falar de inclusão em contextos de tamanha desigualdade e desvantagem social em que se encontra grande parte dos cidadãos brasileiros já pode ser considerado um avanço, principalmente no que diz respeito à parcela PAEE, pois esta esteve historicamente excluída das intenções do Estado e do sistema educacional praticado nas escolas regulares.

No entanto, argumentou-se, neste estudo, que apenas a matrícula na sala comum e no Atendimento Educacional Especializado não representa a garantia dos direitos sociais e educacionais previstos na Constituição Federal (1988), na Lei de Diretrizes e Bases da educação 9394/96, na Resolução n² (2001), e na Política Nacional de Educação Especial na perspectiva da educação inclusiva (2008). Isso porque, estes educandos precisam ser efetivamente submetidos a processos de escolarização que considerem as suas necessidades educativas e estimulem as suas potencialidades.

Neste esteio, o estudo em questão investigou como ocorre a implementação da política de inclusão nas escolas, segundo a perspectiva dos professores da classe comum do município de Oeiras-PI. Nesta oportunidade, observou-se o que postula Ball (1992; 2016), quando destaca que as escolas são ambientes em que as políticas ganham forma a partir das interpretações e das traduções que os profissionais, especialmente os professores, podem ter, considerando o contexto adverso e as diferenças entre o que está escrito nos documentos oficiais e as condições oferecidas para a sua execução.

No que tange ao perfil dos professores pesquisados, verificou-se que, embora todos sejam concursados, apenas três têm formação em Licenciatura Plena em Pedagogia, e apenas uma possui Pós-Graduação na área da Educação Especial. Esse fato constitui um dos grandes entraves para a escolarização do estudante PAEE em uma 
perspectiva inclusiva, tendo em vista que a falta de formação na área da Educação Especial favorece a prevalência de concepções baseadas no modelo médico.

Outras dificuldades apontadas pelos professores de classe comum, relacionam-se à quantidade elevada de alunos por sala; à falta de tempo para planejar as atividades; ao pouco conhecimento na área da educação especial; à ausência de apoio de outros profissionais; à escassez de material didático e ao preconceito. Observou-se também que os professores reclamam da ausência de serviços de apoio de profissionais especializados e de uma estrutura física adaptada para o atendimento adequado a esse público-alvo. Interpretando e recriando a Política de inclusão escolar conforme o contexto em que estão submetidos, acabam por gerar a execução de uma política deturpada do real significado da inclusão do PAEE na escola comum.

Conclui-se que há necessidade de maior investimento na formação inicial dos docentes para o trabalho pedagógico com o estudante PAEE, a fim de desenvolver suas competências e habilidades, além de uma atualização permanente no contexto escolar, propiciada pela comunicação de saberes e experiências entre o professor da classe comum e o professor especializado em Educação especial, tendo em vista a construção coletiva de um planejamento que contemple as especificidades e necessidades educativas de cada estudante. Merece destaque que alguns professores pesquisados afirmam utilizar-se de atividades adaptadas, como desenhos, jogos, brincadeiras, entre outras, para propiciar a participação e a interação dos estudantes PAEE. No entanto, essas estratégias ainda não favorecem a inclusão deste alunado no currículo comum praticado nas escolas e, portanto, não contribuem para a igualdade de oportunidades de aprendizagem do PAEE nas escolas regulares.

Sendo assim, embora na avaliação dos professores pesquisados muito já tenha sido feito em prol da inclusão escolar na rede municipal de Oeiras, as condições ainda não são consideradas favoráveis para a promoção de uma educação que estimule e propicie o desenvolvimento dos educandos PAEE e a sua plena participação nos processos de aprendizagem da escola comum.

Finalmente, vale destacar que para que uma inclusão efetiva venha a ocorrer, não basta que o professor procure individualmente por uma formação adequada; é necessário, sobretudo, investimentos em políticas públicas efetivas, por parte da União, Estado e municípios, no sentido de criar condições estruturais, suportes e apoios escolares que garantam uma verdadeira inclusão do estudante PAEE.

\section{Referências}

BALL, S.J.; BOWE, R. Subject departments and the "implementation" of National Curriculum policy: an overview of the issues. Journal of Curriculum Studies, London, v. 24, n. 2, p. 97-115, 1992.

BALL, S. J. Como as escolas fazem políticas. 23. ed. Ponta Grossa: UEPG, 2016.

BRASIL. Decreto $\mathbf{n}^{\mathbf{0}}$ 6.571, de setembro de 2008. Dispõe sobre o atendimento educacional especializado. Presidência da República. Brasília, DF, 2008.

BRASIL. Decreto $\mathbf{n}^{0} \cdot$ 7.611. Dispõe sobre a educação especial, o atendimento educacional especializado e dá outras providências. Casal Civil, Subchefia para Assuntos Jurídicos, Brasília, DF, 2011. 
BRASIL. Resolução no ${ }^{\mathbf{0}}$ 02/2001. Institui Diretrizes Nacionais para a Educação Especial na Educação Básica. Câmara de Educação Básica, Brasília, DF, 2001.

BRASIL. Portaria Normativa $\mathbf{n}^{\circ}$ 13/2007. Dispõe sobre a criação do Programa de Implantação de Salas de Recursos Multifuncionais, Brasília, DF, 2002.

BUENO, J. G. S. Educação especial brasileira: questões conceituais e de atualidade. São Paulo: EDUC, 2016.

DENARI, F. Um (novo) olhar sobre a formação do professor de educação especial: da segregação à inclusão. In: RODRIGUES, D. (Org.). Inclusão e educação: doze olhares sobre a educação inclusiva. São Paulo: Summus, 2006, p.33-63.

DUTRA, C. P. Política nacional de educação especial na perspectiva da educação inclusiva de 2008: Contexto da criação. In: MANZINI, E. J; OLIVEIRA, J. P; GERMANO, G. D. (Orgs). Política de e para educação especial. Marília: ABPEE, 2018, p.11-30.

FERREIRA, M; PRADO, S. A; CADAVIECO, J. F. Educação inclusiva: o professor como epicentro do processo de inclusão. Revista nacional e internacional de educação inclusiva, v.8, n.1, p. 1-13. março. 2015.

FRASER, M. T. D; GONDIM, S. M. G. Da fala do outro ao texto negociado: discussões sobre a entrevista na pesquisa qualitativa Paideia. Ribeirão Preto. 2004. Disponível em: http://www.scielo.br/ scielo.php?script=sci_arttext\&pid=S0103-863X2004000200004. Acesso em: jan. 2019.

FRANCO, M.L.P.B. Análise de conteúdo. Brasília: Plano Editora, 2003.

FREITAS, M. T. A. A abordagem sócio histórica como orientadora da pesquisa qualitativa. Cadernos de Pesquisa, n. 116, p. 21-39, julho 2002.

GARCIA, R. M. C. Política de educação especial na perspectiva inclusiva e a formação docente no Brasil. Revista Brasileira de Educação, v. 18, n. 52, p. 101-119, jan-mar, 2013.

GLAT, R; NOGUEIRA, M. L. L. Políticas educacionais e a formação de professores para a educação inclusiva no Brasil. Comunicações - caderno do programa de pós-graduação em Educação. Ano 10, n. 1, p. 134-141, junho, 2003.

GODOY, A. S. Introdução à pesquisa qualitativa e suas possibilidades. São Paulo, v. 35, n. 2, p. $57-63,2005$.

KASSAR, M. C. M. A formação de professores para a educação inclusiva e os possíveis impactos na escolarização de alunos com deficiências. Cad. Cedes, Campinas, v. 34, n. 93, p. 207-224, maio-ago. 2014.

LEPRI, C. Viajantes inesperados: notas sobre a inclusão social das pessoas com deficiência.

Tradutores: Ilse Paschoal Moreira, Fernanda landucci ortale. Campinas, SP: Saberes Editora, 2012. 
MAINARDES, J. Análise das políticas educacionais: breves considerações. Contrapontos, v. 9, n. 1, p. 4-16, 2009.

MAINARDES, J. Abordagem do Ciclo de políticas: uma contribuição para análise de políticas educacionais. Educ. Soc., Campinas, v. 27, n. 94, p. 47-69, jan./abr. 2006.

MARTINS, L. A. R.; Inclusão escolar: algumas notas introdutórias. In: MARTINS, L. A. R.; DENERI, F. E.; LIMA, F. J.; PIRES, J.; OLIVEIRA, I. A.; PIRES, G. N. L.; MELO, F. R. L. V.; SILVA, L. G. S.; CAMARGO, E. A. A.; PÁSSARO, A. C. A. (Orgs.). Inclusão: compartilhando saberes. Petrópolis, RJ: Vozes, 2006. p.17- 25.

MENDES, E. G. A radicalização do debate sobre inclusão escolar no Brasil. Revista Brasileira de Educação, São Carlos, n.33, 2006, p. 387- 401.

MENDES, E. G. Histórico do movimento pela inclusão escolar. IN: MENDES, Enicéia Gonçalves. Inclusão marco zero: começando pelas creches. Araraquara, SP: Junqueira\&Marin, 2010, p.11-27.

MENDES, E. G.; CIA, F., TANNÚS-VALADÃO, G. Inclusão Escolar em Foco: 68 Educação Especial em Debate Vitória-ES. a. 1, v.1. n. 01. In: Organização e Funcionamento do Atendimento Educacional Especializado. São Carlos, 2015.

OLIVEIRA, A. A. Inclusão escolar e formação de professores: o embate entre o geral e o específico. IN: MENDES, E. G; ALMEIDA, M. A. A (Orgs). Das margens ao centro: perspectivas para as políticas e práticas educacionais no contexto da educação especial inclusiva. Araraquara, SP: Junqueira\&Marin, 2010, p.141-150.

SILVA, L. A; ABREU, L. C . C. Formação docente: alteridades contemporâneas. v.1, n. 1, artigo $\mathrm{n}^{\circ} 39$, p.529-547, outubro, 2016.

TANNÚS-VALADÃO; VILLARONGA; LACERDA; MENDES. Questionário de Avaliação da Política de inclusão escolar. São Carlos. 2016. 